Recovery, peer support and confrontation in services for people with mental illness and/or substance use disorder

Patrick W. Corrigan, Jonathon E. Larson, David Smelson and Michelle Andra

\section{Summary}

Mental illness recovery has been described as an outcome (symptom free) or process (symptom management) where peer supporters are essential. Whereas, substance use disorder recovery endorses outcome alone: achieving recovery once abstinent. Peer supporters with an abstinence agenda use confrontation for those in denial. Herein, we unpack this distinction.

\section{Declaration of interests}

None.

\section{Keywords}

Mental illness; substance use disorder; recovery; peer support.

\section{Copyright and usage}

(C) The Royal College of Psychiatrists 2019.
Patrick Corrigan (pictured) is a distinguished professor of psychology at Illinois Tech and his research examines mental illness, substance use disorder and the impact of stigma on recovery. Jonathon Larson is an associate professor of psychology at Illinois Tech and his research examines the intersections of mental illness, substance use disorder and employment. David Smelson is a professor of psychiatry at the University of Massachusetts Medical School. His research examines co-occurring mental health and substance use. Michelle Andra is the local recovery coordinator at the WJB Dorn VA Medical Center and her areas of focus are stigma-reduction and suicide prevention interventions for veterans.

Recovery has become a first principle in good practice for people with mental illness and with substance use disorder, with peers evolving as an essential resource for promoting this principle. A position statement by consultant psychiatrists was posted by the Royal College of Psychiatrists and unpacks the complexity of recovery. ${ }^{1}$ The Substance Abuse and Mental Health Services Administration (SAMHSA) in the USA, using a multi-year consensus strategy, proposed a similar definition of recovery for mental illness and also for substance use disorder. ${ }^{2}$ Differences in both sets of definitions were found both within service domains (mental illness and substance use disorder), and, more importantly between the two. Given the roles of peer services in promoting recovery, these definitions may lead to unspoken, disparate expectations about their services. In this editorial, we briefly highlight differences in recovery definitions as well as approaches to peer support. We then describe how therapeutic confrontation may challenge approaches to peer support.

\section{Recovery as an outcome versus a process}

Recovery from mental illness and from substance use disorder has been alternately defined as an outcome or a process. ${ }^{3}$ Recovery from mental illness as the outcome reflects expectations that symptoms and disabilities of even the most serious of psychiatric disorders can remit entirely. In fact, benchmarks of recovery outcome have been defined and may include sustained remission of symptoms that make up a diagnosis to subclinical levels and at least part-time engagement in an instrumental role such as work or school. This perspective partly reflects long-term follow-up research related to the course of schizophrenia that shows that people with the illness can be symptom free despite out-of-date notions of the illness being described as a progressive downhill course.

However, recovery as the outcome has had its detractors because it suggests recovery only occurs in those who are symptom free; it is more of a medical model. Process models have emerged as an alternative. ${ }^{1}$ Namely, recovery is a process whereby people pursue life goals in the spirit of hope despite mental health symptoms. One of many tasks involved in rehabilitation is to help people manage, not eliminate, symptoms and disabilities so they can be successful in their personally defined pursuits.

Recovery in substance use disorder seems to rest on a similar two-factor distinction: outcome versus process. Abstinence is often the outcome in services for people with substance use disorder. The goal is to help people remain free of the addictive substance, a view that is especially prominent in disease models of substance use disorder. ${ }^{4}$ More recently, harm reduction has emerged as an important construct to frame recovery in substance use disorder as more of a process. Harm reduction advocates recognise that abstinence is not the only way to health. ${ }^{5}$ It is an individualised process focused on decreasing the impact of, rather than completely extinguishing, harmful behaviours. Being free of abstinence expectations may promote hope and aspirations.

The consultant psychiatrist statement posted by the Royal College and the SAMHSA definition of recovery related to mental illness recognises the importance of outcome; ${ }^{1,2}$ it does not frame outcome here in terms of being symptom free but rather people overcoming internal and external challenges. However, more prominent in the definitions are ideas consistent with recovery as a process. Recovery is person-driven so that ultimate goals (outcomes!) are defined by the individual and not some external criteria of being 'healed'. Mental illness recovery is defined by many pathways; hence, the process is essential to definition of the concept. However, the SAMHSA definition of recovery seems less equivocal focused solely on substance use disorder outcome. Specifically, the report says, 'abstinence from the use of alcohol, illicit drugs and non-prescribed medications is the goal for those with addictions'. There is no similar mention of process or harm reduction in the substance use disorder definition of recovery. 
Understanding recovery as a process in substance use disorder is complicated by the nuance of the term as it evolved among people with addictions. Some characterise themselves as 'in recovery,' that despite achieving the outcome of abstinence, they still struggle with temptation leading to the 12-step aphorism, 'one step at a time'. This ongoing struggle is reminiscent of the process of recovery in mental illness; that the person with mental illness grapples with recurring symptoms. However, 'in recovery' for mental illness still does not presume the end state of symptom free. One step at a time points to abstinence as the outcome.

\section{The role of peer support}

Support of the person's pathway to goals and aspirations is fundamental to recovery. ${ }^{3}$ Although support might be provided by professionals, emerging evidence suggests that support offered by peers - others with lived experience of mental illness - may be especially beneficial to those on the recovery pathway. ${ }^{6}$ Reviews also show that peer support yielded positive benefits for individuals with substance use disorder. ${ }^{7}$

What are the key ingredients of effective peer support? SAMHSA published a report on peer-support practice guidelines based on a multi-year consensus process that included 1000 members of the International Association of Peer Supporters. ${ }^{8}$ Based on their definition of recovery, the goal of the SAMHSA report was to define ethical and practice guidelines for services provided by peers to people with mental illness and/or substance use disorder. Ethical guidelines included definitions of peer support as, among other things: voluntary, hopeful, open-minded and with equally shared power. The ethical principles correspond with practice guidelines. For example, the voluntary ethic of peer support is accomplished by promoting choice: 'peer supporters do not force or coerce others to participate in peer support services or any services' ${ }^{8}$

\section{Confrontation}

Therapeutic confrontation is one strategy sometimes seen in services for substance use disorder, based on abstinence that leads to a significant difference in peer support between mental illness and substance use disorder domains. Proponents of abstinence often place expectations of responsibility for people addressing the personal substance use disorder. Failure to accept responsibility is denial; confrontation of denial may be needed as a result. ${ }^{9}$ Confrontation is a complex construct that varies from an argumentative, at times hostile, style to a more nuanced approach meant to warn about the potential harm of continued substance use. Of concern is whether confrontation may, at times, lead peer supporters to convince, if not coerce, others with mental illness or substance use disorder to participate in services. Although beyond the scopes of this editorial, research on the relative effectiveness of confrontation would inform this discussion.

Confrontation would be contrary to the first ethic of the SAMHSA guide to peer services meant to promote choice. Some believe that motivational interviewing is rooted in Rogerian client-centred strategies as an alternative to confrontational practices. Harm reduction is a construct from substance use disorder that serves a similar process. ${ }^{5}$

Consider, as an example, the dilemma of confrontation when peer services are key to supported employment. Peer supporters in vocational roles embrace principles described in the individual placement and support (IPS) programme that include rapid job search guided by individual-defined agendas. ${ }^{10}$ IPS is consistent with peer support ethics of self-determination as well as practices such as motivational interviewing and shared decision-making. However, IPS principles and this approach to recovery may be foreign to some peer supporters rooted in the substance use disorder recovery model of abstinence and the need for confrontation. They may view the goals of a person with schizophrenia with multiple admissions to hospital to complete college and graduate school for a career in banking as 'unrealistic'. With confrontation, they will help the person see how this might be a waste of time.

IPS for this group can seem foreign with these peer supporters unable to meet fidelity for effective supported employment. Training for those who value confrontation can seem equally alien when guidelines for addressing unrealistic expectations or denial are not addressed. In addition, service recipients may have difficulty sorting out peer supports adhering to self-determination principles with those believing confrontation has value. The goal of this paper is not to judge the place of confrontation in recovery for substance use disorder or for mental illness. In fact, we empathise with people who recovered from substance use disorder through 12-step programmes with this kind of confrontation. Still, service leaders need to be aware that this distinction continues.

Consider this dilemma from another perspective. Who is the peer in recovery? We think most mental health advocates would refer to people in recovery, not individuals who meet some criteria for being symptom free but rather those pursuing their goals with hope. The definition might be a bit different for peers with substance use disorder. According to existing definitions, peers in recovery are abstinent; they have reached an outcome. Absent from this picture would be the peer in recovery, people meeting their goals despite substance use. These are the people who might benefit from harm reduction. In going forward, definitions need to consider whether they want to qualify its model of recovery as a process by stipulating that abstinence alone is not the goal. This may be a first step for understanding where confrontation fits in recovery.

Patrick W. Corrigan, Distinguished Professor of Psychology, Department of Psychology, Illinois Institute of Technology, USA; Jonathon E. Larson, Associate Professor of Psychology, Department of Psychology, Illinois Institute of Technology, USA; David Smelson, Professor of Psychiatry, Department of Psychiatry, University of Massachusetts Medical School, USA; Michelle Andra, Local Recovery Coordinator, WJB Dorn VA Medical Center, USA

Correspondence: Patrick W. Corrigan, Illinois Institute of Technology, 3424 South State Street, Chicago, IL 60616, USA. Email: corrigan@iit.edu

First received 17 May 2018, final revision 3 Aug 2018, accepted 10 Oct 2018

\section{References}

1 South London and Maudsley NHS Foundation Trust and South West London and St George's Mental Health NHS Trust. Recovery is for All. Hope, Agency and Opportunity in Psychiatry. A Position Statement by Consultant Psychiatrists. SLAM/SWLSTG, 2010 (https://www.rcpsych.ac.uk/pdf/Recovery\%20is\%20for\% 20all.pdf).

2 Substance Abuse and Mental Health Services Administration. SAMHSA's Working Definition of Recovery: 10 Guiding Principles. SAMHSA, 2012. (https:// store.samhsa.gov/shin/content/PEP12-RECDEF/PEP12-RECDEF.pdf).

3 Silverstein SM, Bellack AS. A scientific agenda for the concept of recovery as it applies to schizophrenia. Clin Psychol Rev 2008; 28: 1108-24.

4 Scott CK, Foss MA. Dennis ML: Pathways in the relapse-treatment-recovery cycle over 3 years. J Subst Abuse Treat 2005; 28: S63-72. 
5 Marlatt GA, Larimer ME, Witkiewitz K. Harm Reduction: Pragmatic Strategies for Managing High-Risk Behaviors (2nd edn). Guilford Press, 2011.

6 Sells $D$, Davidson $L$, Jewell C, Falzer $P$, Rowe M. The treatment relationship in peer-based and regular case management for clients with severe mental illness. Psychiatr Serv 2006; 57: 1179-84.

7 Bassuk EL, Hanson J, Greene RN, Richard M, Laudet A. Peer-delivered recovery support services for addictions in the United States: a systematic review. J Subst Abuse Treat 2016; 63: 1-9.
8 Substance Abuse and Mental Health Services Administration. Core Competencies for Peer Workers in Behavioral Health Services. SAMHSA, 2015 (https://www.samhsa.gov/sites/default/files/programs_campaigns/brss_tacs/ core-competencies.pdf)

9 Polcin D. A model for sober housing during outpatient treatment J Psychoactive Drugs 2009; 41: 153-61.

10 Drake RE, Bond GR, Becker DR. Individual Placement and Support: An EvidenceBased Approach to Supported Employment. Oxford University Press, 2012.

\section{psychiatry} in history

\title{
The Royal Society: fasting in the early 18th century
}

\author{
Greg Wilkinson
}

\section{The Woman by Llangollen died: the Derby-Shire Woman recovered}

The Royal Society originates from the first 'learned society' meeting on 28 November 1660 following a lecture at Gresham College by Christopher Wren. This group of natural philosophers and physicians received royal approval and from 1663 became known as 'The Royal Society of London for Improving Natural Knowledge'. Their motto Nullius in verba, from Horace, means 'take nobody's word for it': a determination to withstand authority and to verify all statements by facts determined by experiment. The Society's unique classified papers (1660-1741) include two volumes concerning 'Physick': these comprise 117 national and international communications. Only eight of these are of potential psychiatric interest: two describe lengthy fasting - one in Latin (1666), and the other is cited below; two concern long sleep; and, one each are on catalepsy, swoon, boulimia centenaria ${ }^{1}$ and nostalgia. This minority might be taken to indicate the comparative poverty of contemporaneous interest, theory and method in mental physick among such curious men of science. Even so, over 300 years later: 'We don't know exactly what causes anorexia and other eating disorders'.2

Ile' a/fure You my Curiosity never led me to vifit the Woman by Llangollen; but on my Journey pa/sing by the door I made bold to call; and twas my Fortune to come in as /he was just expiring, $/ 0$ that I saw her not alive; but I discoursd with her Parents both then, and in my return; and with divers others in the Neighborhood. I beleive the Main Matter of Fact is true, that she livd ten Weeks and some odd days without Sustenance, she had livd so before for a fortnight, and alwayes in a trance. But as for the Miracle of it, and her pretended llluminations, I have no faith for them. It may be (for ought I know) a Disorder of Nature in her, and others, on the Defective side, as we sometimes find it in Exces of Appetite: and both very Unaccountable. Where the Flame of Life is weak, little will ferve to maintain it; it may feed upon the Stock already laid up, as in many other Animals that sleep all the Winter. I suppose when Nature ceaseth to crave (as it probably may on divers Occafions) there is little wast made, and a Man may live long without outward Sustenance. Such seems the Case of the Derby-Shire Woman, who is said to have liv'd sixteen Moneths without Meat or Drink: onely her Mouth was now and anointed with a feather [sic]. But/ /he did not sleep or doze altogether, like her of Llangollen; but had her Intervalls of sleep, and Waking, and conversd with Viftants, \& afterward recoverd her Health.

$\mathrm{M}^{r}$ - of - at $\mathrm{M}^{r}$ - of -'s Funerall mentioned one or two in his Neighborhood that has livd so; one (as I remember) 6 Weeks, the other about half a Year; but this latter took some drink now and then, as I was told since; when I see $\mathrm{Mr}$-, perhaps I may be better informed.

For the Woman of Llangollen's Character, I find it agreed upon in Generall, that she was grave, sober, and Religious, but not without a deep tincture of melancholy, being from her Childhood (by the Confe/sion of her Parents) Subject to disquieting thoughts, and frightfull Dreams. She was Conftantly at the Service of the Church but frequented other Meetings; and by some Phra/es and Notions of her Mother's (a Woman of a very fluent Tongue, tho illiterate) I gue/e She read much in Diffenter's Books. From much attention to dark thoughts she came at last to beleive that Something spoke to her, \& gave her advice, \& Comfort against Severe Temptation and Tryalls from her spiritual Enemy. Once/he thought he saw a young Boy in yellow apparell pa/ffiercely by her in the Air, so that she had onely a glance of him; and being at a lo/s to know what he was, the voice told her - It was Originall Sin. ... What ever Opinion others may have of that young Woman (near 30 years of age) I fear She had a high One of her self, \& so had all about her; and lookd upon those raptures /he had as Divine favours: $w^{\text {ch }}$ made her tell her Mother somewhat before /he fell into her last fit - That/he had reveald unto her things beyond Humane Comprehen/ion; that /he would /ay Little to her any more; that /he was going to Christ her Husband, that the Comforter would come to them, if they fervd God; and read to her Our Saviour's Valedictory Discours to his Disciples out of $S^{t} J$ John. She took upon her also to foretell somethings in Ch: and State; $W^{\text {ch }}$ I had no Mind to hear, ... I told her Parents, That her Piety \& Good Meaning, I hop'd, was acceptable to God; the rest might be her Infirmity, ... They were civill and thankfull. I thought they were poor, \& offerd them fomewhat, but they utterly refused, \& said they did not want, and were farr from intending to make profit by their Daughter; and fo, I was told, they answerd divers others. Mar. 9th 1705-6. (Anonymous: Royal Society Archives: Cl.P/14i/59.)

Copyright @ The Royal College of Psychiatrists 2019

\section{References}

1 Browne T. Sir Thomas Browne's Works: Including his Work and Correspondence, Vol IV (ed S Wilkins): 340 . William Pickering, 1835

2 NHS. Overview: Anorexia Nervosa. NHS, 2018 (nhs.uk/conditions/anorexia). 